\title{
Electrochemical Behaviors of Ceftazidime at Gr/GCE and its Interaction with DNA Studied by Fluorescence and CV Method
}

\author{
Yanli Sun, Meifeng Chen, Liguang Chen, Xueliang Wang ${ }^{*}$,Tao Wang* \\ College of Chemistry and Chemical Engineering, Heze University, Heze 274015, Shandong, China \\ *E-mail: yuzywx1@163.com
}

doi: $10.20964 / 2019.07 .44$

Received: 24 December 2018 / Accepted: 10 May 2019 / Published: 10 June 2019

\begin{abstract}
The electrochemical behaviors of CFD (ceftazidime) at a graphene modified electrode (Gr/GCE) were investigated by cyclic voltammetry. Compared with a bare glassy carbon electrode, the Gr/GCE exhibited a significantly enlarged irreversible oxidation peak due to the excellent electron transfer function and catalytic effect of graphene. The peak currents were proportional to CFD concentration of $0.25 \sim 10.0 \mu \mathrm{M}$ and 10.0 75.0 $\mu \mathrm{M}$, with the detection limit of $0.1 \mu \mathrm{M}$. Furthermore, the interaction between CFD and double stranded DNA was studied by electrochemical and fluorescence methods. The results showed that the peak current of CFD decreased remarkably and the fluorescence intensity quenched significantly with the increasing of DNA concentration, which indicated that the CFD molecule intercalated into DNA to form a CFD-DNA complex. In addition, the number of electrons transferred in the electrochemical reaction was calculated based on the electrochemical results to assess the possible interaction mechanisms.
\end{abstract}

Keywords: Ceftazidime detection; Electrochemical sensor; Fluorescence; Graphene; Interaction between CFD and DNA

\section{FULL TEXT}

(C) 2019 The Authors. Published by ESG (www.electrochemsci.org). This article is an open access article distributed under the terms and conditions of the Creative Commons Attribution license (http://creativecommons.org/licenses/by/4.0/). 